\title{
Differential histochemical effects of muscle contractions on phosphorylase and glycogen in various types of fibres: relation to fatigue ${ }^{1}$
}

\author{
ERIC KUGELBERG AND LARS EDSTRÖM \\ From the Department of Neurology, Karolinska Sjukhuset, Stockholm
}

Recent histochemical studies have shown that striated muscle fibres are more heterogeneous than merely white and red. Stein and Padykula (1962), who determined the intensities of succinic dehydrogenase activity of fibres in rat fast and slow muscle (gastrocnemius, soleus), found in addition to the classical white muscle fibres (A fibres) two kinds of red fibres (B and C). Romanul (1964) found in the same muscles eight different types of fibres from the standpoint of the relative amount of several enzymes.

Studies of the properties of single motor units in the limb muscles of the cat and rat have disclosed a wide range of contraction speed, tension output and fatiguability - for example, Gordon and Phillips, 1953; Wuerker, McPhedran, and Henneman, 1965; Appelberg and Emonet-Dénand, 1967; Burke, 1967; Close, 1967). The conclusions drawn from such studies regarding the relation between function and histochemical properties of fibres are based on the assumption that each motor unit is made up of one kind of muscle fibre (Henneman and Olson, 1965; Olson and Swett, 1966; Burke, 1967; Close, 1967). However, so far this has not been proved conclusively.

Investigations into the functional organization of the different types of fibres and mapping of the motor unit would no doubt be furthered if a method were available to differentiate between fibres which had been contracting and those which had not. In the search for a histochemical index we observed that contractions produced striking changes in the phosphorylase activity and glycogen content which varied in the different types of fibres. The histochemical changes are in themselves interesting, since they bear a relationship to muscular fatigue and reflect a metabolic differentiation of different fibres on activation not easy to observe in a heterogeneous muscle with the classical biochemical

${ }^{1}$ This work was supported by a grant from the Swedish Multiple Sclerosis Society. methods. A preliminary account has been reported (Kugelberg and Edström, 1968).

\section{METHODS}

The investigations were carried out on 70 adult albino rats, weighing 200 to $250 \mathrm{~g}$.

PHYSIOLOGICAL METHODS The anterior tibial and soleus muscles were brought into contraction mainly by repetitive electrical shock stimuli to the sciatic nerve. Approximately $2 \mathrm{hr}$ before stimulation, the animal was anaesthetized with $0.5 \mathrm{ml} .2 .5 \%$ pentobarbital (Mebumal) administered intraperitoneally, followed by smaller doses as necessary. With the rat in the prone position on a heated table, the sciatic nerve of one hind limb was exposed and cut. Steel pins were drilled through the tibia near the knee joint and through the calcaneus and clamped so that the leg was rigidly held on the table with the thigh and lower leg at right angles. The foot was fixed in a holder. The tendon of the anterior tibial muscle and the achilles tendon were cut. For recording the tension of the soleus, the gastrocnemius muscle was gently dissected free from the tendon. The tendon of the muscle to be examined was attached with a thin steel wire to a Grass FT 10 force-displacement transducer. The transducer was connected to a BUDD model P-350 Portable Digital Strain Indicator and its output displayed on a Tektronix 502A oscilloscope and photographed. The overall frequency bandwidth of the recording system was $0-50 \mathrm{~Hz}$.

The contractions were recorded nearly isometrically. The optimal initial tension was evaluated before the start of the repetitive shock stimulation. Care was taken to apply the lowest tension giving maximal response, since it was observed that overstretch increased fatigue upon stimulation. The initial tension of the anterior tibial muscle was about $15 \mathrm{~g}$ and of the soleus $8 \mathrm{~g}$. The tension recording device was calibrated before and after each experiment.

Action potentials were recorded in some experiments. Thin wire electrodes, isolated except for the tip, were introduced into the muscle through a fine hypodermic needle. The wire was hooked over the tip of the needle. The needle was then withdrawn leaving the wire in the muscle. 
The sciatic nerve was stimulated with a pair of chlorided silver electrodes about $1 \mathrm{~cm}$ distal to its cut end. The nerve lay in a pool of mineral oil. A voltage of $0.5-1 \mathrm{~V}$, three times the rheobase and supramaximal for the large motor fibres, was used. Stimulation times were $30 \mathrm{sec}, 2,5,10,30 \mathrm{~min}$, and 1 and $2 \mathrm{hr}$.

In a few experiments single motor nerve fibres to the anterior tibial muscle were stimulated with conventional technique for comparison with stimulation of the whole nerve.

HISTOCHEMICAL METHODS Muscles from both the stimulated and the non-stimulated sides were subjected to identical procedures in each experiment, non-stimulated muscles being used as controls. .

The muscles were cut into $10 \times 5 \mathrm{~mm}$ pieces and rapidly frozen by immersion in propane cooled to $-160^{\circ} \mathrm{C}$ with liquid nitrogen. Serial sections were cut at $16 \mu$ in a cryostat at $-20^{\circ} \mathrm{C}$. Only three successive sections were spared for each procedure in order to enable the histochemical characterization of the muscle fibres with different methods over short segments of fibres. This permits identification and comparison of the individual fibres in the different slides. The following procedures were applied in each experiment: (1) succinic dehydrogenase (Pearse, 1960); (2) phosphorylase (Eränkö and Palkama's (1961) modification of the Takeuchi and Kuriaki (1955) method). Brief fixation of the sections in alcohol at $-20^{\circ}$ increased the contrast between different types of fibres. Incubation time was generally $30 \mathrm{~min}$; (3) Periodic acid-Schiff (PAS) for glycogen (Pearse, 1960).

Some specimens were further examined for fat with Sudan black, esterases by the Shnitka and Seligman (1961) modification of Holt and Withers' (1958) method.

\section{RESULTS}

HISTOCHEMICAL CLASSIFICATION OF NON-STIMULATED MUSCLE FIBRES

ANTERIOR TIBIAL MUSCLE From the standpoint of succinic dehydrogenase activity three different types of fibres were distinguished similar to the A, $\mathbf{B}$, and $\mathbf{C}$ groups found by Stein and Padykula (1962) in the gastrocnemius muscle (Fig. 1a). The A fibres are large with low activity, the $\mathrm{C}$ fibres small with intense activity. The $B$ fibres show within a large population a continuum between $\mathbf{A}$ and $\mathrm{C}$ as regards intensity of staining reaction. Within a smaller area the changes are more stepwise, since a number of adjacent fibres often exhibit the same intensity. Further investigations may show whether such fibres belong to the same motor unit. In the individual fibres the esterase activity closely paralleled that of succinic dehydrogenase.

The level of phosphorylase activity, on the other hand, shows for most fibres a negative image in relation to the enzymes mentioned above (Dubowitz and Pearse, 1960) (Fig. 1b). The majority of A fibres are dark blue, the $B$ fibres of various lighter shades $\mathbb{D}$ of blue or bluish purple, and the $\mathrm{C}$ fibres light bluish purple.

The PAS reaction does not lend itself to fibre- $\overline{\overline{0}}$ typing. Inconstant variations in staining intensity ${ }_{\infty}$ occur between different fibres. The $\mathrm{C}$ fibres are then generally among the lighter coloured fibres (Fig. 1c).

The A fibres predominate in the superficial $\underset{2}{2}$ portion of the muscle and the $\mathbf{B}$ and $\mathbf{C}$ fibres in the deeper portion. The $\mathbf{A}$ and $\mathbf{B}$ fibres comprise $\overrightarrow{\overline{\overrightarrow{ }}}$ about $41 \%$, and $\mathrm{C}$ about $18 \%$ of the fibres $(1,885 \div$ fibres counted in eight different squares located $\overline{0}$ to minimize the bias of uneven distribution). The $\overline{\bar{\sigma}}$ cross-sectional areas of the muscle occupied by $\mathbb{\Phi}$ the $\mathrm{A}, \mathrm{B}$, and $\mathrm{C}$ groups were $55 \%, 34 \%$, and $11 \%$ respectively.

SOLEUS Stein and Padykula (1962) recognized $=$ two different types of fibres, B and C, which they $\omega^{\prime}$ considered identical with the $B$ and $C$ fibres of gastrocnemius. Romanul (1964) found three $\frac{7}{0}$ different types.

Relevant to this investigation is whether the ir soleus types of fibre occur in the anterior tibiaf is Succinic dehydrogenase activity showed thre $\vec{\sigma}$ levels of intensity in soleus. The majority of fibre have a rather low activity, about 1 in 10 have $\mathbb{Q}-$ slightly higher activity. In addition there are sma霖 fibres with intense activity. The first two correspong $\frac{\vec{O}}{\square}$ as regards intensity of succinic dehydrogenas activity to $B$ fibres and the third to C. Howeve $\overrightarrow{5} \cdot \vec{b}$ the first two differ from the B fibres of the anteriof tibial in a more even distribution of staining and finer granules. Moreover, esterase activity is relatively high in soleus B fibres as compared with B fibres of anterior tibial of equal intensity of $\bar{\partial}$ succinic dehydrogenase activity.

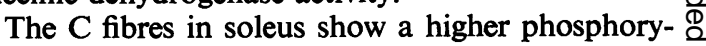
lase activity and a lower esterase activity than the $\overrightarrow{\vec{F}}$ B fibres in contrast to the $\mathrm{C}$ fibres in anterior tibial, $\frac{\mathrm{O}}{3}$ which had lower phosphorylase and higher esterase $\bar{\nexists}$ activity than B. Thus it would appear that none of the three different types of fibres in the soleus are histochemically entirely identical with those of the anterior tibial. Our findings in soleus are in good agreement with those of Romanul (1964).

\section{HISTOCHEMICAL EFFECTS OF STIMULATION}

In an initial series of experiments the effect of stimulus $\frac{D}{O}$ frequencies of $20-100 / \mathrm{sec}$, which produce a fused contraction, were investigated. This causes a rise $N$ in intramuscular pressure and considerable $\mathrm{N}$ obstruction of bloodflow. Such muscles fatigue 옹 

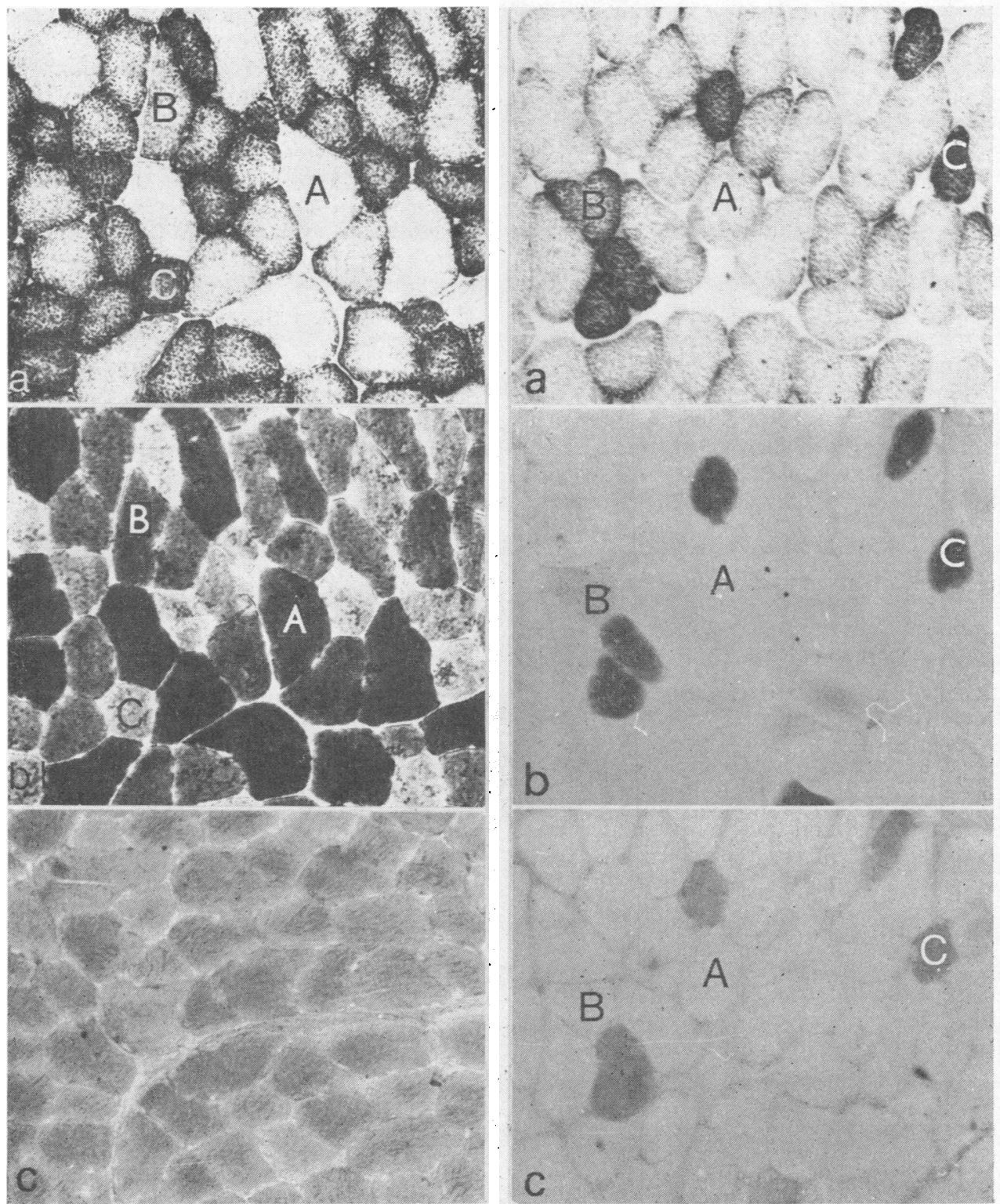

FIG. 1

FIG. 2

FIG 1. Rat 70. Serial sections of unstimulated anterior tibial incubated for (a) succinic dehydrogenase and (b) for phosphorylase. Identical $A, B$ and $C$ fibres are marked in both sections: (c) shows PAS. $\times 165$.

FIG. 2. Rat 70. Serial sections of anterior tibial stimulated for $10 \mathrm{~min}$ at 10/sec incubated for (a) succinic dehydrogenase and (b) for phosphorylase. (c) PAS. Identical $A, B$ and $C$ fibres are marked in the sections for orientation. $A$ fibres show no phosphorylase activity, $B$ fibres little or none, $C$ fibres high activity. $A$ and $B$ fibres are $P A S$ negative, $C$ fibres show slight increase. $\times 165$. 
rapidly and it was thought that maximal histochemical effects would be produced. It was soon observed that the histochemical changes bore no strict relationship to the frequency of stimulation. In fact the effect of stimulation for $10 \mathrm{~min}$ at $50 / \mathrm{sec}$ was less than at $10 / \mathrm{sec}$. The rapid decline of contraction at $50 / \mathrm{sec}$, presumably due to failure of transmission at the neuromuscular junction, apparently protected the muscle fibre (Krnjevic and Miledi, 1958).

In order to obtain a better defined load on the muscle fibres, low frequencies of $5-10 / \mathrm{sec}$ were mostly applied. The histochemical changes then developed more slowly and were easier to follow in the different types of fibres. Moreover, the contractions would not be affected by ischaemia since, as shown by Kjellmer (1964) in the calf muscles of cats, maximal vasodilatation is reached at about $5 / \mathrm{sec}$ and blood flow is still high at $10 / \mathrm{sec}$.

ANTERIOR TIBIAL MUSCLE Succinic dehydrogenase No changes were observed in succinic dehydrogenase or esterase activity in stimulated muscles as compared with non-stimulated (Fig. 2a). Thus these enzymes can be used for fibre typing in the stimulated preparation, which enables comparison of staining intensity with identical types of fibres in nonstimulated control muscles. The following procedure was used to estimate the effect of stimulation. In the section incubated for succinic dehydrogenase all fibres within a certain area were counted and typed as $\mathbf{A}, \mathbf{B}$, or $\mathrm{C}$ fibres. The same fibres were then examined in the sections incubated for phosphorylase or PAS (Table I and II).

Phosphorylase The phosphorylase activity in the A fibres is so strongly positive in the controls that any increase in the stimulated muscles might easily be masked. The control muscle is not strictly unstimulated since the preparation, including freezing, causes a certain amount of contraction which might well affect the highly reactive enzyme.

In muscles stimulated at a frequency of $5 / \mathrm{sec}$ for 5-10 min, most of the A fibres showed no phosphorylase activity, while most of the B fibres and some of the $\mathbf{C}$ fibres showed a high phosphorylase activity. Thus the activity in the B fibres closely resembled that in the unstimulated A fibres (Table I).

At a stimulus frequency of $10 / \mathrm{sec}$ for $5-10 \mathrm{~min}$ all the $\mathbf{A}$ fibres and most of the $\mathbf{B}$ fibres showed no phosphorylase activity, while $90 \%$ of the C fibres showed a high activity closely paralleling that in the unstimulated A fibres (Fig. 2b, Table I).

During prolonged stimulation at $5 / \mathrm{sec}$ the phosphorylase activity in the $\mathrm{A}, \mathrm{B}$, and $\mathrm{C}$ fibres gradually reverted to the prestimulated levels. This was clearly seen after $30 \mathrm{~min}$ stimulation. After
$2 \mathrm{hr}$ stimulation the activity was essentially the $Z$ same as in the control muscle (Table II).

$P A S$ The PAS reaction is not suitable for the evaluation of small changes owing to uneven staining in the controls. Therefore only a strong increase or decrease in relation to controls may be accepted as aw stimulation effect.

A stimulus frequency of $5 / \mathrm{sec}$ for $30 \mathrm{sec}$ showed a decrease in PAS reaction first in the A fibres. After 5 min stimulation, more than $90 \%$ of the $A$ fibres showed a negative reaction (Fig. 3b). Stimulation for $1 \mathrm{hr}$ and $2 \mathrm{hr}$ gave the same? negative reaction. Stimulation at $5 / \mathrm{sec}$ had less $\frac{\overline{ }}{\bar{N}}$ effect on activity in B fibres. After $30 \mathrm{sec}$ stimulation $\frac{\bar{s}}{-}$ there was no change; after 2 min stimulation there $\stackrel{\triangle}{\perp}$ was a slight increase in some fibres. After 5-10 $\mathrm{min}$ stimulation some fibres showed a slight decrease $\overrightarrow{-}$ but scarcely any were PAS negative even after $2 \mathrm{hr}$. stimulation. At this time, however, a large pro- $\vec{\omega}$ portion of the fibres were clearly less strongly stained $\stackrel{s}{S}$ than in the control (Table II).

At a frequency of $10 / \mathrm{sec}$ the decrease appeared? earlier and was more marked. One hundred per cent $\stackrel{\omega}{\rightarrow}$ of the A fibres and most of the B fibres were PAs ir negative after $5-10$ min stimulation (Fig. $2 \vec{\Phi} \frac{\vec{Q}}{\mathrm{G}}$
Table I).

The $\mathrm{C}$ fibres showed no decrease in PAS reactio $\frac{\text { क् }}{2}$ 을

TABLE I

HISTOCHEMICAL EFFECTS OF 10 MIN STIMULATION

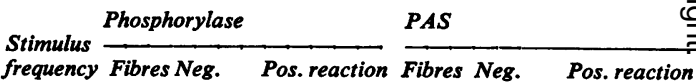

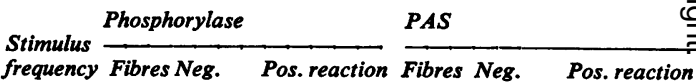
(no.) reaction +++- (no.) reaction ++ or $+-\square$

\begin{tabular}{|c|c|c|c|c|c|c|c|c|c|}
\hline $\begin{array}{l}\text { 5/sec } \\
\text { R66 }\end{array}$ & $\begin{array}{l}\text { A } 48 \\
\text { B } 65 \\
\text { C } 43\end{array}$ & $\begin{array}{r}42 \\
0 \\
0\end{array}$ & $\begin{array}{r}2 \\
52 \\
13\end{array}$ & $\begin{array}{r}0 \\
7 \\
29\end{array}$ & $\begin{array}{l}4 \\
6 \\
1\end{array}$ & $\begin{array}{l}\text { A } 109 \\
\text { B } 88 \\
\text { C } 75\end{array}$ & $\begin{array}{r}103 \\
1 \\
0\end{array}$ & $\begin{array}{r}4 \\
72 \\
75\end{array}$ & $\begin{array}{r}2 \\
15 \\
0\end{array}$ \\
\hline $\begin{array}{l}10 / \mathrm{sec} \\
\text { R70 }\end{array}$ & $\begin{array}{l}\text { A } 300 \\
\text { B } 50 \\
\text { C } 37\end{array}$ & $\begin{array}{r}300 \\
33 \\
0\end{array}$ & $\begin{array}{r}0 \\
1 \\
33\end{array}$ & $\begin{array}{l}0 \\
7 \\
4\end{array}$ & $\begin{array}{l}0 \\
9 \\
0\end{array}$ & $\begin{array}{l}\text { A } 300 \\
\text { B } 51 \\
\text { C } 37\end{array}$ & $\begin{array}{r}300 \\
45 \\
0\end{array}$ & $\begin{array}{r}\mathbf{0} \\
\mathbf{1} \\
\mathbf{3 7}\end{array}$ & \\
\hline
\end{tabular}

++ denotes increase, + no change, - decrease.

TABLE II

HISTOCHEMICAL EFFECTS OF PROLONGED STIMULATION AT 5/SEC

\begin{tabular}{|c|c|c|c|c|c|c|c|c|}
\hline \multirow{2}{*}{$\begin{array}{l}\text { Stimulus } \\
\text { time }\end{array}$} & \multicolumn{4}{|c|}{ Phosphorylase } & \multicolumn{4}{|l|}{$P A S$} \\
\hline & $\begin{array}{l}\text { Fibres } \\
\text { (no.) }\end{array}$ & $\begin{array}{l}\text { Neg. } \\
\text { reaction }\end{array}$ & $\begin{array}{l}\text { Pos. } \\
++\end{array}$ & $\begin{array}{c}\text { reaction } \\
+-\end{array}$ & $\begin{array}{l}\text { Fibres } \\
\text { (no.) }\end{array}$ & $\begin{array}{l}\text { Neg. } \\
\text { reaction }\end{array}$ & $\begin{array}{c}\text { Pos. reactio } \\
++ \text { or }+\end{array}$ & \\
\hline $\begin{array}{l}1 \mathrm{hr} \\
\mathrm{R} 64\end{array}$ & $\begin{array}{l}\text { A } 84 \\
\text { B } 46 \\
\text { C } 144\end{array}$ & $\begin{array}{l}\mathbf{0} \\
\mathbf{0} \\
\mathbf{0}\end{array}$ & $\begin{array}{r}55 \\
3 \\
0\end{array}$ & $\begin{array}{rr}27 & 2 \\
40 & 3 \\
5 & 139\end{array}$ & $\begin{array}{l}\text { A } 101 \\
\text { B } 60 \\
\text { C } 68\end{array}$ & $\begin{array}{r}99 \\
0 \\
0\end{array}$ & $\begin{array}{r}0 \\
35 \\
68\end{array}$ & $\begin{array}{r}2 \\
25 \\
0\end{array}$ \\
\hline $\begin{array}{l}2 \mathrm{hr} \\
\mathbf{R} 65\end{array}$ & $\begin{array}{l}\text { A } 217 \\
\text { B } 34 \\
\text { C } 56\end{array}$ & $\begin{array}{l}0 \\
0 \\
0\end{array}$ & $\begin{array}{r}155 \\
4 \\
0\end{array}$ & $\begin{array}{rr}62 & 0 \\
29 & 1 \\
12 & 44\end{array}$ & $\begin{array}{l}\text { A } 178 \\
\text { B } 28 \\
\text { C } 48\end{array}$ & $\begin{array}{r}177 \\
1 \\
0\end{array}$ & $\begin{array}{r}0 \\
6 \\
48\end{array}$ & $\begin{array}{r}1 \\
21 \\
0\end{array}$ \\
\hline
\end{tabular}

++ denotes high, + moderate, - low activity. 
at $5 / \mathrm{sec}$ for $2 \mathrm{hr}$. On the contrary, they tended to be more intensely stained than control $\mathrm{C}$ fibres after a few minutes of stimulation.

The differential decrease in glycogen seems to be little known in the mammalian muscle. However, in the pigeon pectoralis George and Nene (1965) observed that stimulation caused exhaustion of the glycogen reserves in the large white fibres and an increase in the small red fibres.

After $10 \mathrm{~min}$ stimulation at $10 / \mathrm{sec}$, the PAS reaction recovered slowly over a period of 1-2 hr. The A fibres recovered somewhat more slowly than the B fibres.

Single motor nerve fibre stimulation In a few experiments single motor nerve fibres were

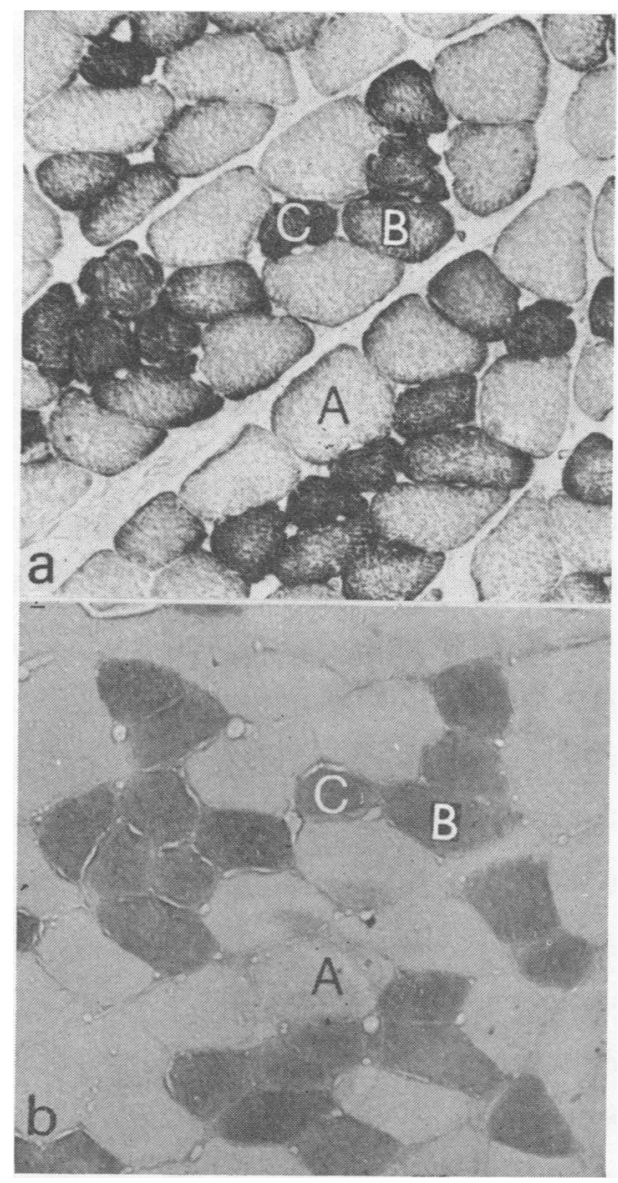

FIG. 3. Rat 66. Serial sections of anterior tibial stimulated for 10 min at $5 /$ sec incubated for (a) succinic dehydrogenase, (b) PAS. The A, B and C fibres are identical in both sections. Only $A$ fibres are PAS negative. $\times 165$. stimulated, which seemed to give essentially the same effects as stimulation of the whole nerve. It suggested that the fibres of the motor units are scattered and of largely uniform histochemical composition. This will be dealt with in detail in a following paper.

SOLEUS No changes were observed in soleus fibres under the conditions above. Intermittent high frequency stimulation however eventually decreased the intensity of the PAS reaction.

\section{FATIGUE AND HISTOCHEMICAL CHANGES}

In the anterior tibial muscle $5 / \mathrm{sec}$ stimulation caused a transient 'staircase' rise followed by a more or less linear decrease to a steady state after about $5 \mathrm{~min}$. The level of tension was $40-55 \%$ below the initial twitch tension measured in six preparations and could be maintained for several hours. Slight interference with circulation however caused a rapid fall of tension.

After cessation of the stimulus the twitch tension increased transiently, due to post-tetanic potentiation, but attained the earlier value after 1-3 min. The recovery of the twitch was remarkably slow. After 5 min stimulation recovery was complete after a rest of about $2 \mathrm{hr}$.

Since both the muscle action potential and twitch tension declined, failure of transmission to the muscle fibres may be present but it could be shown that the contractile system of the muscle fibres had failed. This was apparent during rest, since the action potential recovered within $5-15 \mathrm{~min}$, at a time when the twitch tension had not recovered (Fig. 4). Thus the action potential arrived at and passed over the muscle fibre, which did not respond adequately.

Before accepting the decline in twitch tension as a sign of fatigue, it is necessary to exclude the possibility that it was due to a decrease in re-excitation of the nerve fibres by the strong synchronous muscle action potential (Lloyd, 1942; Leksell, 1945). As shown by Brown and Matthews (1960), a backresponse can be greatly reduced by means of double stimulation, either by two half-volleys delivered with an interval of $0.6 \mathrm{msec}$ (Merton, 1951) or by applying a second maximal stimulus immediately after the first. Neither before nor after the tetanus did these methods provoke any change in twitch amplitude. Thus in the Mebumal anaesthetized rat the back-response was insignificant and not responsible for the tension decline. Accordingly, under the experimental conditions fatigue was a muscular phenomenon presumably caused by a 


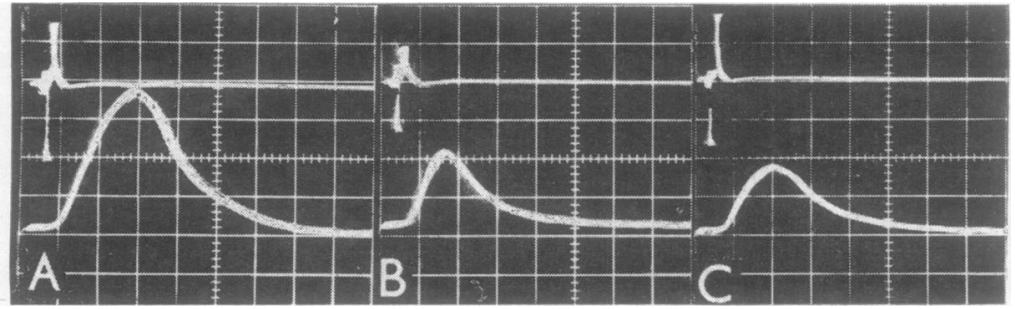

FIG. 4. A. Action potential (upper record) and twitch tension (lower record) at commencement of stimulation at $5 / \mathrm{sec}$. B. After 5 min stimulation. C. After 10 min rest showing recovery of action potential but not of twitch tension. Vertical grid $20 \mathrm{~g}$, horizontal $10 \mathrm{msec}$.

block in excitation-contraction coupling (Eberstein and Sandow, 1963) and/or by exhaustion of available energy for contraction.

A stimulus frequency of $10 / \mathrm{sec}$ produced a further $10 \%$ decline in tension as compared with $5 / \mathrm{sec}$, measured in two preparations, where fusion of the tetanus did not occur. However, in most preparations stimulation was complicated by fusion which was caused by an increase in contraction and relaxation times during the first few minutes of stimulation. To avoid fusion the relation between stimulus frequency and fatigue was also tested in a slightly different way.

The steady state level was first estimated at $2 / \mathrm{sec}$ stimulation for $20 \mathrm{~min}$ immediately followed by $5 / \mathrm{sec}$ stimulation for $10 \mathrm{~min}$, followed by $8 / \mathrm{sec}$ stimulation for $5 \mathrm{~min}$ and so on. To obtain a steady state, longer stimulation times were necessary at the low than at the high frequencies. When the muscle was gradually fatigued in this way fusion did not appear at stimulus frequencies below $20 / \mathrm{sec}$. The resulting decline in steady state was essentially the same as with the previous method-a $53 \%$ decline at $5 / \mathrm{sec}$ and a further $10 \%$ decline at $11 / \mathrm{sec}$ (Fig. 5). It is seen that the steady state level curve shows an initial steep fall but at $5 / \mathrm{sec}$ flattens out to a much lower slope. Owing to the longer contraction time of soleus a similar curve cannot be constructed for this muscle as fusion occurs already at $8 / \mathrm{sec}$.

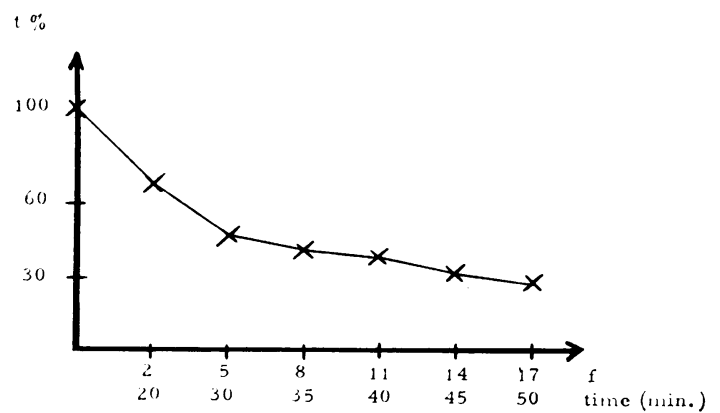

FIG. 5. Development of fatigue expressed in steady state level at different stimulus frequencies. Full description in text.
However, it was apparent that soleus lacks the steep initial part of the curve. The tension declined only about $10 \%$ at $5 / \mathrm{sec}$.

Since A fibres do not occur in soleus it is tempting to ascribe the marked fatiguability of the anterior tibial at low stimulus frequencies mainly to these fibres. Some obvious correlation exists. The steep $\overrightarrow{0}$ decline of the fatigue curve flattens out at a $5 / \mathrm{sec}, \vec{\overrightarrow{ }}$ when almost all $\mathbf{A}$ fibres are phosphorylase and $\omega_{\sigma}$ PAS negative. The tension decline is then $40-55 \%$ of the initial tension, a reasonable value from this point of view, since the A fibres occupy about $55 \% \dot{\omega}$ of the cross-sectional area of the muscle. Moreover, $\overrightarrow{i r}$ the steady state level at $2 / \mathrm{sec}$ stimulation was about $A$ $30 \%$ below the initial value. A histochemical chec $\vec{v}$ of the muscle showed that at this point about $60 \%$ 윽 of the A fibres were phosphorylase and PASnegative compared with an expected $55 \%$.

If glycogen storage and glycogenolysis are cruciag for A fibre function this is not so for many B fibres At a stimulus frequency of $10 / \mathrm{sec} 66 \%$ of the $B$ fibres were phosphorylase negative and $88 \%$ PAS negative. However, tension declined only a further $10 \%$ instead of an expected decline of $20-26 \%$ based on calculations on a cross-sectional area with $34 \%$ B fibres.

\section{DISCUSSION}

One of the prime objects of this study was to find a histological index of previous contractions. This was obtained in the anterior tibial in nearly $100 \%$ of A fibres, about $95 \%$ of B fibres, and about $90 \%$ of the $\mathrm{C}$ fibres at a stimulus frequency of $10 / \mathrm{sec}$ for $10 \mathrm{~min}$. 'The changes were confined to phosphorylase and to glycogen. No changes were observed in soleus fibres. The results were obtained by shock stimulation, which produced a synchronized contraction of the whole muscle. A few observations suggest that contractions of single motor units give the same effects. Stimulation of a single motor nerve fibre to the anterior tibial gave the expected reactions. This would seem to provide a picture of the anatomical distribution and histochemical properties of the motor unit, which permits cor- 
relation between its anatomical, histochemical, and functional characteristics.

The striking changes in phosphorylase activity produced by stimulation are not consistent with the common view that the histochemical method of Takeuchi and Kuriaki (1955) and its modifications demonstrate the total phosphorylase content of the fibre. Biochemical studies have shown that stimulation has no effect on total phosphorylase. Yet histochemically stimulation produced a strong increase in both B and C fibre activity. Moreover muscular fatigue caused rapid disappearance of phosphorylase activity in A and $\mathbf{B}$ fibres. The phosphorylase activity demonstrated histochemically was obviously not a static phenomenon but dependent on the functional state of the muscle fibre.

One explanation of the dynamic behaviour of phosphorylase activity might be that the histochemical method reflected the level of active phosphorylase rather than the total phosphorylase. From the brilliant studies of Cori and Cori it is well known that the contraction process in muscle is associated with a reversible change in phosphorylase between an inactive and active form, a change mediated by two separate enzymes. The active form increases rapidly during contraction and decreases more slowly during rest. Muscular fatigue is associated with an almost complete disappearance of the active form (Cori, 1945; Cori and Illingworth, 1956; Danforth and Helmreich, 1964). If this explanation is valid, the histochemical findings complement the biochemical studies in that activation and inactivation of phosphorylase have been shown to proceed after a different time course in the various fibre types, being fastest in $A$ and slowest in $\mathrm{C}$. This is also indicated by the different speed of glycogen break down in different types of fibres.

Another possible explanation which must be considered is that the histochemical changes in phosphorylase are secondary to the changes in glycogen. The histochemical demonstration of phosphorylase is based on the ability of the enzyme to synthetize glycogen from glucose-1-phosphate in the presence of glycogen as a primer. To this end glycogen is added to the incubation medium. If this happens to be ineffective as a primer the reaction could well increase or decrease in intensity parallel with changes in the glycogen storage of the fibre. This occurred early during stimulation. However, during prolonged stimulation, the phosphorylase activity in A and B fibres recovered from being virtually absent to prestimulated levels while the glycogen content remained low or decreased.

During stimulation the glycogen disappeared at the fastest rate in A fibres, followed by the B fibres.
Within each fibre group there was a spectrum of different rates of glycogen breakdown. We believe, however, it is justifiable to speak of two different groups of fibres in this respect rather than a smooth continuum, since it was possible by adjusting the stimulus to cause disappearance of PAS reaction in almost $100 \%$ of the $\mathbf{A}$ fibres, while almost all $B$ fibres were little affected (Fig. 3b). However, it is obvious that the difference between $A$ and $B$ fibres is much less than between $B$ and $C$ fibres. The $C$ fibres were much more resistant. In fact the PAS reaction increased in $\mathrm{C}$ fibres at a stimulus intensity which caused it to disappear in both A and B fibres. Whether the increase was the result of an accelerated synthesis or a decrease rate of breakdown is not clear. Thus, although both $\mathbf{B}$ and $\mathbf{C}$ fibres are undoubtedly red (Stein and Padykula, 1962), the glycogen reaction in the $\mathrm{B}$ fibres was more similar to that in white $A$ fibres than in the red $C$ and soleus fibres. In A and B fibres glycogen breakdown occurs at a high rate. At rest, however, resynthesis to prestimulated values is slow.

Romanul (1964) and Dawson and Romanul (1964), on the basis of available histochemical and quantitative biochemical studies including their own investigations, classified the many fibre types into three main groups. Group I. The classical white fibre characterized by the highest capacity for breakdown of glycogen to lactate (anaerobic), low oxidative metabolism, low myoglobin content and low lipid metabolism. Group II. Glycolysis (anaerobic) approaching that in I, high oxidative capacity, high myoglobin content, moderate lipid metabolism. Group III. Low capacity for glycolysis, high oxidative metabolism, high myoglobin content and very high lipid metabolism. The A fibres of the anterior tibial muscle belong to group I, the B fibres apparently to group II and the $\mathrm{C}$ fibres and the soleus type of fibres to group III.

The $A$ and $B$ fibres are capable of glycogen breakdown at a high speed. However, glycogen resynthesis is unbalanced by breakdown at a surprisingly low stimulus frequency at synchronized contractions of the whole muscle: $40 \%$ of the A fibres were PAS negative at a stimulus frequency of $2 / \mathrm{sec}$ for $10-20 \mathrm{~min}$ and almost all at $5 / \mathrm{sec}$ for $5 \mathrm{~min}$ - that is, after some $1,500-2,000$ contractions. It is suggested that the fatigue observed at low frequency stimulation was due to failure of the contractile mechanism of the A fibres, which had exhausted their glycogen reserves. In view of the low oxidative capacity of these fibres this is a plausible explanation since oxidation is the only process which can keep the fibre in balance. The B fibres with their higher oxidative capacity have greater possibilities to compensate exhaustion of 
the glycolytic machinery. Neither in the $\mathrm{C}$ fibres nor in the soleus types of fibre was any strain on the glycogen reserve observed and it is questionable whether glycogen was metabolized at any considerable rate under these conditions.

If it is correct that the A fibres fatigue after some 2,000 contractions at a stimulus frequency of $5 / \mathrm{sec}$, it is clear they must be protected from frequent or continuous use under physiological conditions, especially since recovery is slow. The only way to protect the A fibres is to use them sparingly over short periods of time. It is therefore to be expected that the A fibres are organized within high threshold motor units recruited only during strong or quick contractions (Ashworth, Grimby, and Kugelberg, 1967) and innervated by phasically discharging motoneurones (Granit, Henatsch, and Steg, 1956).

Studies on the nature of muscular fatigue need not be summarized here, since most investigations have been performed under different experimental conditions-for example, frog muscles, in vitro preparations, high frequency stimulation causing fused tetanus, etc. Our observations show that muscular factors are of importance in the development of fatigue, as has been stressed by Merton (1954) for strong isometric voluntary contraction in man. However, it should be emphasized that our results have been obtained in one species of animal, the rat.

\section{SUMMARY}

The effect of low frequency shock stimulation of the sciatic nerve on the histochemical properties of anterior tibial and soleus muscles has been investigated in albino rat. In the anterior tibial muscle, changes in phosphorylase activity and glycogen content were most pronounced in the A fibres, less in the $\mathrm{B}$ fibres, and least in the $\mathrm{C}$ fibres. Over $90 \%$ of the fibres exhibited distinct changes. Preliminary observations suggest that stimulation of single motor nerve fibres give similar effects which provide a picture of the anatomical distribution and histochemical properties of the motor unit. The soleus fibres showed no changes.

In A fibres no increase in phosphorylase activity was observed but may have been masked. Rapid decrease and disappearance of phosphorylase activity was associated with disappearance of PAS reaction. In $\mathbf{B}$ fibres there was initial strong increase followed by decrease at a slower rate than in $\mathrm{A}$. In $\mathbf{C}$ fibres an initial strong increase was at a slower rate than in $B$.

During prolonged stimulation the phosphorylase activity slowly returned to prestimulated values.
The dynamic behaviour of phosphorylase suggest $\bar{z}$ that the histochemical method demonstrated active rather than total phosphorylase.

At a stimulus frequency of $10 / \mathrm{sec}$ the PAS reaction in $A$ fibres rapidly decreases and dis appears followed by the B fibres at a slower rate In C fibres there was, if anything, an increase.

Low frequency stimulation caused fatigue in the anterior tibial muscle. Observations suggest that i $\vec{k}$ was mainly the result of exhaustion of the glycolytic: machinery of the A fibres in which glycogenolysis? unbalanced resynthesis at remarkably low stimulation? frequencies.

\section{REFERENCES}

Appelberg, B., and Emonet-Dénand, F. (1967). Motor units of the first superficial lumbrical muscle of the cat. J. Neurophysiol., $30, \overrightarrow{0}$ 154-160.

Ashworth, B., Grimby, L., and Kugelberg, E. (1967). Comparison of voluntary and reflex activation of motor units. Functionaf organization of motor neurones. J. Neurol. Neurosurg Psychiat., 30, 91-98.

Brown, M. C., and Matthews, P. B. C. (1960). The effect on a musclę twitch of the back-response of its motor nerve fibres. J. Physiol. (Lond.), 150, 332-346.

Burke, R. E. (1967). Motor unit types of cat triceps surae muscie. $\mathrm{T}$ Ibid. 193, 141-160.

Close, R. (1967). Properties of motor units in fast and slow skelequl $\vec{G}$ muscles of the rat. Ibid. 193, 45-55.

Cori, G. T. (1945). The effect of stimulation and recovery on he응 phosphorylase $a$ content of muscle. J. biol. Chem., 158, 333-3\%.

-, and Illingworth, B. (1956). The effect of epinephrine and other glycogenolytic agents on the phosphorylase $a$ content of muscle. Biochim. biophys. Acta (Aust.) 21, 105-110.

Danforth, W. H., and Helmreich, E. (1964). Regulation of glycolys in muscle. I. The conversion of phosphorylase $b$ to phospho lase $a$ in frog sartorius muscle. J. biol. Chem., 239, 3133-313\%

Dawson, D. M., and Romanul, F. C. A. (1964). Enzymes in musct. II. Histochemical and quantitative studies. Arch. Neurol., $\Pi, \infty$ 369-378.

Dubowitz, V., and Pearse, A. G. E. (1960). A comparative histo- $\square$ chemical study of oxidative enzyme and phosphorylase activity in skeletal muscle. Histochemie, 2, $105-117$.

Eberstein, A., and Sandow, A. (1963). Fatigue mechanisms in muscle fibres, in The Effect of Use and Disuse on Neuromuscular Function, pp. 515-526. Czechoslovak Academy of Sciences, 으 Prague.

Eränkö, O., and Palkama, A. (1961). Improved localization of phosphorylase by the use of polivinyl pyrrolidone and high $\overline{\bar{O}}$ substrate concentration. J. Histochem. Cytochem., 9, 585.

George, J. C., and Nene, R. V. (1965). The effect of exercise on the glycogen content of the red and white fibres of the pigeon pectoralis muscle. J. Anim. Morphol. Physiol., 12, No. 2, ? 246-248.

Gordon, G., and Phillips, C. G. (1953). Slow and rapid components in a flexor muscle. Quart. J. exp. Physiol., 38, 35-45.

Granit, R., Henatsch, H. D., and Steg. G. (1956). Tonic and phasic ventral horn cells differentiated by post-tetanic potentiation in cat extensors. Acta physiol. scand., 37, 114-126.

Henneman, E., and Olson, C. (1965). Relations between structure $?$ and function in the design of skeletal muscles. $J$. Neurophysiol., 28, 581-598.

Holt, S. J., and Withers, R. F. J. (1958). Studies in enzyme histo- 0 chemistry: V. An appraisal of indigogenic reactions for esterase $\supset$ localization. Proc. roy. Soc. B., 148, 520-532.

Kjellmer, I. (1964). The effect of exercise on the vascular bed of skeletal muscle. Acta physiol. scand., 62, 18-30.

Krnjevic, K., and Miledi, R. (1958). Failure of neuromuscular $N$ propagation in rats. J. Physiol., 140, 440-461.

Kugelberg, E., axd Edström, L. (1968). Histokemiska förăndringar vid $N$ muskel-kontraktion. Transactions of the Swedish neurol. soc., 1967. Nord. Med., in press. 
Leksell, L. (1945). The action potential and excitatory effects of the small ventral root fibres to skeletal muscle. Acta physiol. scand., 10, suppl. 31, 84 .

Lloyd, D. P. C. (1942). Stimulation of peripheral nerve terminations by active muscle. J. Neurophysiol., 5, 153-165.

Merton, P. A. (1954). Voluntary strength and fatigue. J. Physiol. (Lond.), 123, 553-564.

- (1951). Contractions of muscle produced by synchronous and asynchronous motor volleys. J. Physiol, 112, $6 P$.

Olson, C. B., and Swett, C. P. A. (1966). Functional and histochemical characterization of motor units in a heterogeneous muscle (flexor digitorum longus) of the cat. J. comp. Neurol., 128, 475-498.

Pearse, A. G. E. (1960). Histochemistry: Theoretical and Applied, 2nd ed. J. \& A. Churchill, London.
Romanul, F. C. A. (1964). Enzymes in muscle: I. Histochemical studies of enzymes in individual muscle fibers. Arch. Neurol., 11, 355-368.

Shnitka, T. K., and Seligman, A. M. (1961). Role of esteratic inhibition on localization of esterase and simultaneous cytochemical demonstration of inhibitor sensitive and resistant enzyme species. J. Histochem. Cytochem., 9, 504-527.

Stein, J. M., and Padykula, H. A. (1962). Histochemical classification of individual skeletal muscle fibers of the rat. Amer. J. Anat., 110, 103-123.

Takeuchi, T., and Kuriaki, H. (1955). Histochemical detection of phosphorylase in animal tissues. J. Histochem. Cytochem., 3, 153-160.

Wutrker, R. B., McPhedran, A. M., and Henneman, E. (1965). Properties of motor units in a heterogeneous pale muscle (M. gastrocnemius) of the cat. J. Neurophysiol., 28, 85-99. 